Diş hekimliği

öğrencilerinde

periodontal risk

faktörlerinin ve

periodontal

hastalık-sistemik

bağlantı bilgisinin

değerlendirilmesi

\section{Evaluation of risk factors and periodontal disease-systemic connection knowledge in dentistry students}

Dr. Öğr. Üyesi Ebru Özkan Karaca

Yeditepe Úniversitesi, Diș Hekimliği Fakültesi,

Periodontoji A.D., İstanbul

Orcid ID: 0000-0003-1835-554X

Gelis tarihi: 17 Haziran 2019

Kabul tarihi: 25 Haziran 2019

doi: 10.5505/yeditepe.2019.05935

\section{Yazışma adresi:}

Dr. Öğr. Üyesi Ebru Özkan Karaca

Yeditepe Úniversitesi, Diş Hekimliği Fakültesi,

Periodontoji A.D.

Bağdat cad. No:238/3A Göztepe, 34728, İstanbul

Tel: (216)3636044

Faks: (216)3636211

E-posta: ebru.ozkan@yeditepe.edu.tr, esmaebrukaraca@gmail.com
ÖZET

Giriş: Bu çalışma, dördüncü ve beşinci sınıf dişhekimliği öğrencilerinin periodontal hastalıklarla ilgili sistemik faktörlerini belirleme yeteneğini, sistemik hastalığı olan ve olmayan farklı derecelerde periodontal hastalığı olan bireylerin risk analizlerini ve klinik karar verme becerisini uygulama yeteneğini değerlendirmiştir.

Gereç ve Yöntem: Bu çalışmada, öğrencilerin periodontal hastalık risk faktörlerini ve periodontal hastalığı olan bireylerdeki klinik karar verme yetkinliğini değerlendirmek amacıyla bir anket formu uygulanmıştır. Niteliksel verilerin karşılaşıııılmasında Ki-Kare testi, Fisher's Exact Ki-Kare testi, Continuity (Yates) Düzeltmesi ve Mc Nemar testi kullanıldı. Niceliksel verilerin gruplar arasında karşılaştırmalarında ise Mann Whitney U Test, grup içi değerlendirmelerinde Wilcoxon sign test kullanıldı. Anlamlılı $\mathrm{p}<0.05$ düzeyinde değerlendirildi.

Bulgular: Çalışmaya cevap verme oranı yüzde $86^{\prime}$ dır. Öğrencilerin belirlenen periodontal risk faktörleri içerisinden doğru olarak en az \%40 ve üzerinde seçtiği 3 risk faktörü: Kontrol altında olmayan diyabet, $\geq 6 \mathrm{~mm}$ posterior cep ve sigara kullanımı 'dır. Öğrencilerin aldıkları bilgiye duydukları güven ve risk faktörü bilgisi üst sınıf öğrencilerinde artış göstermiştir.

Çalışma, öğrencilerin periodontal hastalıkları etkileyen kritik hastalıkları ve risk faktörlerini oldukça iyi bildiklerini ve tedavi konusunda özgüven sahibi olduklarını ortaya koymuştur. Buna karşın bilgi ile uygulamalı klinik muhakeme kurma arasında bir boşluk olduğunu göstermiştir.

Sonuçlar: Öğrenciler risk faktörlerini analiz etmedeki becerilerini klinik senaryolarda kullanamamışlardır. Bu sonuçlar, periodontal hastaların yönetiminde klinik karar vermeyi geliştirmek için diş hekimliği müfredatının gözden geçirilmesi gerektiğini göstermektedir.

Anahtar kelimeler: Klinik karar verme, periodontal hastalık, risk faktörleri

\section{SUMMARY}

Aim: This study evaluated the ability of fourth and fifth grade dental students to determine systemic conditions related to periodontal diseases, the most important risk factors for achieving treatment of patients, and the ability to apply this knowledge to make clinical decisions regarding periodontal treatment.

Materials and method: A twenty-one-item questionnaire was used in Yeditepe Faculty of Dentistry students to gain knowledge and confidence about clinical decision making at the beginning and end of the year. In order to compare the quantitative data Chi-Square Test, Fisher's Exact Chi-Square test, Continuity (Yates) Correction and Mc Nemar tests were used. For the comparison of qualitative data between the groups, Mann Whitney $U$ Test and for assessments to be made within the group Wicoxon sign test was used. Significance was evaluated at $p<0.05$ 
value.

Results: The response rate was 86 percent. Periodontal risk factors were accurately selected by at least 40 percent of students in both classes; these were poorly controlled diabetes, $\geq 6 \mathrm{~mm}$ pockets posteriorly and smoking. The confidence and risk factor knowledge of the students increased in the higher grade students.

Conclusion: Although the students' ability to recognize critical risk factors affecting treatment and referral is good; however, clinical application of this information has shown a gap between knowledge and applied reasoning. These results indicate that the dental curriculum should be reviewed to improve clinical decision-making in terms treatment criteria in periodontal patient management.

Keywords: clinical decisions, periodontal disease, risk factors

\section{Giriş}

Periodontal hastalık; periodonsiyumu oluşturan sert ve yumuşak dokuların bakteriyel kronik iltihabıdır. ${ }^{1}$ Bir tür gram negatif oral enfeksiyon olan kronik enflamatuar periodontal hastalıklar, dünya genelinde insan nufusunun yaklaşık \%50 'sini etkilemektedir. ${ }^{2}$ Diş hekimleri tarafından teşhis edilip kayıt altına alınması gereken periodontal hastalık belirtilerinin başında; gingivitis ve buna bağlı meydana gelen dişeti kanaması, diştaşı oluşumu, çürük, dişlerde sallanma, dişeti çekilmesi, alveol kemiği kaybı ve diş kayıpları gelmektedir. ${ }^{3}$ Yapılan çalışmalar bazı modifiye edilebilen ve edilemeyen risk faktörünün periodontal hastalıkların başlamasında ve ilerleyişinde etki edebileceğini göstermektedir. ${ }^{4}$ Bu faktörler arasında yetersiz ağız hijyeni, sigara kullanımı, kontrol edilemeyen diyabet, periodontal hastalıkların geçmiş öyküsü, genetik yatkınlık, düşük eğitim seviyesi, 6 mm üzerinde periodontal cep derinliği, düzensiz diş hekimi ziyareti, yaş, stres ve spesifik patojenik mikroorganizmalar bulunur., ${ }^{4,5}$

Son zamanlarda yapılan çalışmalar periodontal hastalığın dolaylı olarak vasküler olayların riskini, oluşmasını ve ilerlemesini etkileyebileceğini, aterosleroz ve buna bağlı diğer hastalıklar (kardiyovasküler hastalık, iskemik inme, Alzheimer, demans, kronik böbrek hastalıkları) için önemli bir bağımsız risk faktörü olduğunu öne sürmektedir. ${ }^{6} \mathrm{Bu}$ bilgiler ışığında, genel diş hekimlerinin doğru periodontal tanı koymak, uygun tedavi yapmak için iyi eğitimli olmaları ve ayrıca gerektiğinde periodontistlere zamanında ve doğru yönlendirmeleri yapmaları konusunda da iyi aydınlatılmaları gerekir.? Diş hekimliğinde eğitim ve öğretim müfredatı, diş hekimliği öğrencilerinin mezun olduktan sonra, genel diş hekimliği bakımını bağımsız olarak sağlayabilmeleri için gerekli olan yetkinlikleri (bilgi, beceri ve tutumlar) edinmelerini sağlamalıdır. Periodontal hastalığın birçok sistemik hastalık için bir risk faktörü olabi- leceğini ve tüm dünyada yüksek prevalansta olduğunu ortaya çıkaran kanıtlar gözönüne alındığında, genel diş hekimlerinin periodontal hastalığı olan hastaların üstesinden gelmek için daha kapsamlı bir şekilde eğitilmesi gerektiğini ortaya koymaktadır. ${ }^{8}$

Son zamanlarda yapılan çalışmalar, genel diş hekimlerinin, özellikle erken evrelerde, yetersiz tanı yetenekleri sebebiyle periodontal hastalığı teşhis etmede zorlandığını göstermektedir.7,9 Lee ve arkadaşlarının yaptığı bir çalışmada, genel diş hekimlerinin periodontal hastalığı olan bireyleri tedavi etmede isteksiz olduğunu bildirmişlerdir. ${ }^{7}$ Ayrıca, diş hekimliği müfredatının öğrencileri periodontal hastalığı olan bireylere nasıl hazırladığını ve bu alanda yetkinlik, zaman ve doğruluk geliştirdiklerini değerlendirmek için yeni araştırmalara intiyaç olduğunu belirtmişlerdir. Bu çalışmanın amacı, diş hekimliği öğrencilerinin sistemik hastalığı olan ve olmayan farklı derecelerde periodontal hastalığı olan bireylerin risk analizlerini ve klinik karar verme becerisini değerlendirmektir.

\section{GEREÇ VE YÖNTEM}

Araştırma Yeditepe Üniversitesi Diş Hekimliği Fakültesi Bilim Kurulu tarafından onaylandı. Araştırma kapsamında kullanılacak anket Yeditepe Üniversitesi Diş Hekimliği Fakültesi 4. Sınıf ve 5.sınıf öğrencileri üzerinde uygulandı. Benzerliği sağlamak ve anketlerin yalnızca öğrencilerin eğitim programları tarafından tanımlanmasını sağlamak için sınıflar için renk kodları kullanıldı. Çalışmanın amacı, detayları ve katıımın tamamen gönüllülük esası ile olduğu hakkında öğrenciler bilgilendirildi. Ankete katılanlardan gönüllü olduğunu gösteren onam formu alındı. Anketler akademik yılın başında (A1) ve yılın bitiminden bir hafta önce (A2) öğrenciler tarafından dolduruldu. Çalışmada Williams ve ark. ${ }^{10}$ tarafından daha önce kullanılan ve doğrulanan orijinal anket soruları kullanıldı.

Çalışmada kullanılan 22 maddelik anket soruları 2 etki alanı başlığında ikiye bölündü. Birinci etki alanı periodontal hastalıklar, risk faktörleri ve tedavileri konusunda tutum ve özdeğerlendirmeyi kapsadı. Değerlendirme 5 puanlık Likert skalası kullanılarak; 1: kesinlikle katımıyorum 5: kesinlikle katılıyorum şeklinde yapıldı. Ikinci etki alanı periodontal hastalık ve klinik karar verme yetkinliğini değerlendirmek üzere klinik senaryolar verilerek hazırlandı. Çalışmada elde edilen bulgular değerlendirilirken, istatistiksel analizler için IBM SPSS Statistics 22 (IBM SPSS, Türkiye) programı kullanıldı. Niteliksel verilerin karşılaştırılmasında ise Ki-Kare testi, Fisher's Exact Ki-Kare testi, Continuity (Yates) Düzeltmesi ve Mc Nemar testi kullanıdı. Anlamlılı $\mathrm{p}<0,05$ düzeyinde değerlendirildi.

\section{BULGULAR}

Toplam 95 öğrenciden 82'si (\%86) çalışmaya katıldı. Kırkyedi beşinci sınıf öğrencisinden 42'ü (\%93,3), 43 dördüncü sınıf öğrencisinden 40'ı (\%85) çalışmaya katıldı. Çalışmaya katılan öğrencilerin dağılımı Tablo 1'de görül- 
mektedir.

Tablo 1. Çalışmaya katılan öğrencilerin demografik dağılımları

\begin{tabular}{|l|l|l|}
\hline & 5. sınıf & 4. sinıf \\
\hline Toplam öğrenci & 45 & 50 \\
\hline $\begin{array}{l}\text { Toplam cevap } \\
\text { veren öğrenci }\end{array}$ & $42(\% 93.3)$ & $40(\% 85)$ \\
\hline Kadın & $24(\% 57,14)$ & $25(\% 62,5)$ \\
\hline Erkek & $18(\% 42,85)$ & $15(\% 37,5)$ \\
\hline
\end{tabular}

Cevaplar isimsiz olduğundan, bireysel öğrenci düzeyinde bilgi, tutum ve özgüven değişimleri ilişkilendirilemedi. Dönem başı ve dönem sonu arasındaki karşılaştırmalar yalnızca toplanmış veriler değerlendirilerek yapıldı. Tablo 1 'de çalışmaya katılan öğrencilerin demografik dağılımlarını gösterilmektedir.

Çalışmaya katılan 4. ve 5. Sınıf öğrencilerinin 'Periodontal enflamasyonun tamamen ortadan kaldırılamaması hastaların hayatlarını tehdit eden sistemik durumlara olan yatkınlıklarını arttırabilir' sorusuna verdiği cevaplar arasında dönem başında ve dönem sonunda istatistiksel olarak anlamlı bir farklılık bulunmamaktadır $(p>0,05)$. 4.sınıf öğrencilerinin; dönem başında kesinlikle katılıyorum deme oranları \%35 iken, dönem sonunda bu oran \%47,5'e yükselmiş ancak istatistiksel olarak anlamlı bulunmamıştır. 5.sınıf öğrencilerinin; dönem başında verdikleri cevaplara göre dönem sonu cevaplarında görülen değişim istatistiksel olarak anlamlıdır ( $p: 0,000 ; p<0,05)$. Dönem başında kesinlikle katılıyorum deme oranları \%31 iken, dönem sonunda bu oran \%66,7'ye yükselmiştir.

Çalışmaya katılan öğrencilere 'Diyabet ve periodontal hastalık arasında doğrudan nedensel bir ilişki vardır' sorusu yöneltilmiş ve sınıflar arasında ve dönem başı ve sonunda verdikleri cevaplar arasında anlamlı bir farklılık bulunmamıştır ( $p>0.05$ ). 4.sınıf öğrencilerinin; bu soruya dönem başında verdikleri cevaplara göre dönem sonu cevaplarında istatistiksel olarak anlamlı bir değişim görülmezken ( $p>0.05), 5$. sınıf öğrencilerinin; dönem başında verdikleri cevaplara göre dönem sonu cevaplarında görülen değişim istatistiksel olarak anlamlıdır (p:0.000; $\mathrm{p}<0.05)$. Dönem başında kesinlikle katılıyorum deme oranları \%45,2 iken, dönem sonunda bu oran \%69'a yükselmiştir.

Periodontoloji alanındaki eğitimimin, beni, periodontal hastalıkları tedavi etmek konusunda, 10 sene ya da daha önce eğitim almış olan pratisyen diş hekimlerinden daha donanımlı hale getirdiğine inanıyorum' sorusuna 4.sınıf öğrencilerinin; dönem başında verdikleri cevaplara göre dönem sonu cevaplarında görülen değişim istatistiksel olarak anlamlıdır ( $p: 0,012 ; p<0,05)$. Dönem başında katılıyorum deme oranları \%40 iken, dönem sonunda bu oran $\% 22,5^{\prime}$ e inmiştir.

Bir periodontiste yönlendirmem gereken hastaları tespit etme kabiliyetime güveniyorum sorusuna 4 .sınıf ve 5 .sınıf öğrencilerinin dönem başı cevapları arasında istatistiksel olarak anlamlı farklıık bulunmaktadır (p:0.004; p<0.05). 5 . sınıfların dönem başında katılıyorum ve kesinlikle katılıyorum deme oranları, 4.s ınıflardan anlamlı şekilde yüksektir. 4. sınıf öğrencilerinin; bu soruya dönem başında verdikleri cevaplara göre dönem sonu cevaplarında görülen değişim istatistiksel olarak anlamlıdır ( $\mathrm{p}: 0.000 ; \mathrm{p}<0.05)$. Dönem başında katılıyorum deme oranları \%42,5 iken, dönem sonunda bu oran \%62,5'e yükselmiştir. 5.sınıf öğrencilerinin; soruya dönem başında verdikleri cevaplara göre dönem sonu cevaplarında görülen değişim istatistiksel olarak anlamlıdır ( $p: 0,014 ; p<0,05)$. Dönem başında katılıyorum deme oranları \%69 iken, dönem sonunda bu oran \%57,1'e düşmüştür.

'Farklı periodontal hastaların diş yüzeyi temizliği ve kök yüzeyi düzleştirmesine nasıl yanıt vereceğini öngörmemi sağlayacak yeterli bilgiye sahip değilim' sorusuna verilen cevaplarda sınıflar arasında ve dönemler arasında istatistiksel olarak anlamlı bir farklıık bulunmamaktadır ( $p>0,05)$. 4.sınıf öğrencileri dönem başı ve sonunda $\% 42,5$ oranında bu soruya katılmıyorum cevabı verirken, bu oran 5 . sınıflarda dönem başında $\% 28,2$ ve sonunda $\% 35,7$ olarak kayıt edilmiştir. Alınan sonuçlar öğrencilerin büyük kısmının başlangıç periodontal tedavi sonucunda alacakları yanıt ile ilgili yeterli bilgiye ve klinik özgüvene sahip olmadıklarını göstermektedir.

'Glikozillenmiş hemoglobini (HbA1c)'si 7,0 ve molar bölgelerinde $6 \mathrm{~mm}$ derinliğinde interproksimal cepleri olan bir hasta, pratisyen bir hekim tarafından rahatlıkla idare edilebilir' sorusuna sınıflar ve dönemler arasında istatistiksel olarak anlamlı bir farklıık bulunmamaktadır ( $p>0.05$ ). Dönem başında \%62,5 oranında 4. sınıf ve \%68,5 oranında 5. sınıf öğrencisi soruya katılıyorum ve kesinlikle katılıyorum cevabı verirken bu oran dönem sonunda 4 . Sınıflarda aynı kalırken 5 . sınıfta \%86,2 ye yükselmiştir.

'Diş hekimleri, periodontal hastalıklar ve sistemik hastalıklar arasındaki ilişkiyi ortaya koyan yeni bilgiler ışığında, tam olarak iyileşmeyen periodontal hastalığı olan hastaları, uzmana yönlendirmek konusunda daha istekli olmalılardır' sorusuna sınıflar arasında dönem başında ve dönem sonunda verdikleri cevaplar arasında istatistiksel olarak anlamlı bir farklıık bulunmamaktadır ( $p>0.05$ ). Buna karşın, 4. sınıf öğrencilerinin dönem başında 'kesinlikle katılıyorum' deme oranları \%52,5 iken, dönem sonunda bu oran $\% 67,5^{\prime}$ e yükselmiştir ve görülen değişim istatistiksel olarak anlamlıdır ( $p: 0,030 ; p<0,05)$. 5.sınıf öğrencilerinin; soruya dönem başında verdikleri cevaplara göre dönem sonu cevaplarında görülen değişim istatistiksel olarak anlamlıdır ( $p: 0,000 ; p<0,05)$. Dönem başında kesinlikle katılıyorum deme oranları \%40,5 iken, dönem sonunda bu oran $\% 76,2$ 'ye yükselmiştir.

Öğrencilere klinik karar verme yetkinliğini değerlendirmek için iki klinik senaryo verildi. Bunlarda birincisinde 7 mm'nin üstünde birkaç adet periodontal cebe sahip bir 
hastanın diş yüzeyi ve kök düzleştirmesinden oluşan başlangıç periodontal tedavi yapılmasının ardından ceplerin $5.0 \mathrm{~mm}$ ye düştüğü bildirildi. Bu senaryoya göre hastanın tedavisi ile ilgili seçenekler sunuldu. Sınıflar arasında soruya dönem başında ve dönem sonunda verdikleri cevaplar arasında istatistiksel olarak anlamlı bir farklılık bulunmamaktadır ( $p>0,05)$. 4. Sını öğrencilerinin cevaplarında dönemler arasında anlamlı bir değişim görülmezken ( $p>0,05), 5 . s ı n ı$ öğrencilerinin; ' 3 ay sonra yeniden değerlendiririm' cevabına dönem başına göre dönem sonu cevaplarında görülen değişim istatistiksel olarak anlamlıdır ( $p: 0,033 ; p<0,05)(\% 57,1$ ve \%66,7).

Verilen diğer klinik senaryoda öğrencilere furkasyon ve mukogingival problemleri olan bir hastanın klinik bilgileri verilerek hastaya yapılacak müdahale alternatifleri önerildi. Öğrencilerin büyük çoğunluğu hastaların 'başlangıç periodontal tedavilerinin kendileri tarafından tamamlanması ve sonrasında destekleyici periodontal tedaviye alınması' seçeneğini tercih etti. 5. sınıf öğrencilerinin dönem başında "başlangıç periodontal tedavi yapılması ve sonrasında destekleyici periodontal tedavi kapsamında takip edilmesi" cevabı oranları (\%88.1), 4.sınıf öğrencilerinden (\%65) istatistiksel olarak anlamlı düzeyde yüksektir ( $p: 0,027 ; p<0,05)$. 5.sınıf öğrencilerinin soruya dönem sonunda aynı cevabı verme oranları (\%71.4), 4. sınıf öğrencilerinden (\%47.5) istatistiksel olarak anlamlı düzeyde yüksektir $(p: 0,047 ; p<0,05)$.

4.sınıf öğrencileri; tedaviye aynı cevaba dönemler arasında görülen değişim istatistiksel olarak anlamlıdır ( $p: 0,016 ; p<0,05)$. Dönem başında 6 ay sonra yeniden deme oranlarına göre (\%65), dönem sonunda görülen düşüş $(\% 47,5)$, istatistiksel olarak anlamlıdır.

Çalışmaya katılan öğrencilere periodontal hastalık risk faktörlerinin bilgisini ölçmek amacıyla ankette bulunan faktörler arasında en önemli buldukları ve kendi başlarına tedavi etmekte zorlanabilecekleri ilk dört faktörü işaretlemeleri istendi. Listelenen risk faktörlerinin / klinik bulguların her birini seçen öğrencilerin oranına ilişkin tanımlayıcı veriler Tablo 2'de gösterilmektedir.
Tablo 2. Dişhekimliği öğrencilerinin klinikte periodontal hastalığı olan bir hastada kendi başlarına tedavi etmekte zorlanacaklarını düşündükleri en kritik risk faktör-

\begin{tabular}{|c|c|c|c|c|c|}
\hline \multicolumn{3}{|l|}{ Risk faktörleri } & \multirow{2}{*}{$\begin{array}{l}\text { 4.sınıf } \\
\text { n (\%) } \\
40(\% 100)\end{array}$} & \multirow{2}{*}{$\begin{array}{l}\begin{array}{l}5 . \sin ı f \\
\text { n (\%) }\end{array} \\
42(\% 100)\end{array}$} & \multirow{2}{*}{$\begin{array}{l}\mathbf{p} \\
-\end{array}$} \\
\hline Yüksek Plak Skoru & DB & Yok & & & \\
\hline & DS & Yok & $40(\% 100)$ & $42(\% 100)$ & - \\
\hline \multirow[t]{3}{*}{$\leq 5 \mathrm{~mm}$ anterior cep } & $\mathrm{DB}$ & Evet & $26(\% 65)$ & $32(\% 76,2)$ & ${ }^{19} 0,384$ \\
\hline & DS & Evet & $24(\% 60)$ & $29(\% 69)$ & ${ }^{1 a} 0,532$ \\
\hline & & ${ }^{2} \mathrm{p}$ & 0,500 & 0,250 & \\
\hline \multirow[t]{2}{*}{ Kardiyovasküler hastalık } & $\mathrm{DB}$ & Yok & $40(\% 100)$ & $42(\% 100)$ & - \\
\hline & DS & Yok & $40(\% 100)$ & $42(\% 100)$ & - \\
\hline \multirow[t]{3}{*}{ Sintf II furkasyon defekti } & $\mathrm{DB}$ & Evet & $16(\% 40)$ & $24(\% 57,1)$ & ${ }^{1 \mathrm{a}} 0,183$ \\
\hline & DS & Evet & $16(\% 40)$ & $30(\% 71,4)$ & ${ }^{a} 0,008^{*}$ \\
\hline & & ${ }^{2} \mathrm{p}$ & 1,000 & $0,031^{*}$ & \\
\hline \multirow[t]{2}{*}{40 yaşından büyük } & $\mathrm{DB}$ & Yok & $40(\% 100)$ & $42(\% 100)$ & - \\
\hline & DS & Yok & $40(\% 100)$ & $42(\% 100)$ & - \\
\hline \multirow[t]{3}{*}{ Konrol altunda olmayan diyabet } & $\overline{\mathrm{DB}}$ & Evet & $24(\% 60)$ & $25(\% 59,5)$ & ${ }^{1 \mathrm{a}} 1,000$ \\
\hline & DS & Evet & $27(\% 67,5)$ & $22(\% 52,4)$ & ${ }^{1 \mathrm{a}} 0,242$ \\
\hline & & ${ }^{2} \mathrm{p}$ & 0,250 & 0,250 & \\
\hline \multirow[t]{3}{*}{$\geq 6 \mathrm{~mm}$ posterior cep } & $\overline{\mathrm{DB}}$ & Evet & $19(\% 47,5)$ & $20(\% 47,6)$ & ${ }^{16} 0,991$ \\
\hline & DS & Evet & $15(\% 37,5)$ & $25(\% 59,5)$ & ${ }^{1 \mathrm{a}} 0,076$ \\
\hline & & ${ }^{2} \mathrm{p}$ & 0,125 & 0,063 & \\
\hline \multirow[t]{2}{*}{ Düzenli diş hekimi kontrolü yok } & $\mathrm{DB}$ & Yok & $40(\% 100)$ & $42(\% 100)$ & - \\
\hline & DS & Yok & $40(\% 100)$ & $42(\% 100)$ & - \\
\hline \multirow[t]{2}{*}{ Sinff II mobilite } & $\mathrm{DB}$ & Yok & $40(\% 100)$ & $42(\% 100)$ & - \\
\hline & DS & Yok & $40(\% 100)$ & $42(\% 100)$ & - \\
\hline \multirow{3}{*}{$\begin{array}{l}\text { Daha önce yapılan diş yüzeyi temizliği, } \\
\text { kök yüzey düzleştirmesine cevap vermemiş }\end{array}$} & $\overline{\mathrm{DB}}$ & Evet & $14(\% 35)$ & $26(\% 61,9)$ & ${ }^{19} 0,027^{*}$ \\
\hline & DS & Evet & $28(\% 70)$ & $19(\% 45,2)$ & ${ }^{1 \mathrm{a}} 0,041^{*}$ \\
\hline & & ${ }^{2} \mathrm{p}$ & $0,000^{*}$ & $0,016^{*}$ & \\
\hline \multirow[t]{2}{*}{ Sigara kullanımı } & DB & Yok & $40(\% 100)$ & $42(\% 100)$ & - \\
\hline & DS & Yok & $40(\% 100)$ & $42(\% 100)$ & - \\
\hline \multirow[t]{2}{*}{ Çoklu ilaç kullanımı } & $\mathrm{DB}$ & Yok & $40(\% 100)$ & $42(\% 100)$ & - \\
\hline & DS & Yok & $40(\% 100)$ & $42(\% 100)$ & - \\
\hline \multirow[t]{2}{*}{ Aile öyküsü } & $\overline{\mathrm{DB}}$ & Yok & $40(\% 100)$ & $42(\% 100)$ & - \\
\hline & DS & Yok & $40(\% 100)$ & $42(\% 100)$ & - \\
\hline \multirow[t]{3}{*}{40 yaşından daha genç } & $\mathrm{DB}$ & Evet & $0(\% 0)$ & $1(\% 2,4)$ & ${ }^{1 \mathrm{c}} 1,000$ \\
\hline & DS & Evet & $2(\% 5)$ & $1(\% 2,4)$ & ${ }^{1 c} 0,611$ \\
\hline & & ${ }^{2} \mathrm{p}$ & 0,500 & 1,000 & \\
\hline
\end{tabular}

Uzman paneli sonrasında seçilen 6 risk faktörü içerisinden 4. ve 5. sınıf öğrencilerinin her iki dönemde de $\% 40$ ve üzerinde seçtiği 3 risk faktörü: Kontrol altında olmayan diyabet, $\geq 6 \mathrm{~mm}$ posterior cep ve sigara kullanımı 'dır. Çalışmaya katılan öğrencileri çok büyük çoğunluğu kardiyovasküler hastalık, yüksek plak skoru, düzensiz dişhekimi kontrolü, çoklu ilaç kullanımı, mobilite ve ailesel öyküyü risk faktörü olarak işaretlemişlerdir.

\section{TARTIŞMA}

Modern dişhekimliği eğitiminin amacl, mezun olduktan sonra hastaların etkin ve güvenli bakımı için sorumluluk alabilen bilgili, yetkin ve yetenekli bir diş hekimleri eğitmektir. ${ }^{11} 2006$ 'da, AAP, periodontal tedaviyi yalnızca periodontolog tarafından veya genel diş hekimi ile birlikte tedavi edilmesini ele alan kılavuzlar oluşturmuştur. ${ }^{12} \mathrm{Bu}$ nunla birlikte, klinik karar vermede genel diş hekiminin bilgi, beceri ve yetenekleri yerine geçemeyecekleri için kılavuzlar yeterli gelmemektedir. Periodontal tanı ve tedavi planlamasına dahil olan klinik karar verme sürecinde çoklu faktörlerin varlığı, periodontal hastalıkların karmaşık patofizyolojisi nedeniyle klinik bir tanıya ulaşmak için zorlu bir yorum ve gerekçe gerektirir. ${ }^{13}$ Son yillarda periodontal hastalıkların sistemik hastalıklar üzerine olan etkilerine ilișkin bulguların artması, genel dișhekimlerinin sağlık sistemi içerisindeki önemini arttırmıştır. Buna karşın teşhis, tedavi ve sevk kararları almak genel diş hekimleri arasında deneyimlerinden bağımsız olarak önemli 
zorluklar olmaya devam etmektedir.

Çalışmamızdan elde edilen veriler sonuçlar, dişhekimliği öğrencilerinin periodontal hastalıkların sistemik durumlar üzerindeki etkileri konusunda oldukça olumlu tutumları olduğunu, periodontal hastalığı etkileyen risk faktörlerinin iyi bildiklerini ve periodontal hastaları yönetme konusunda eğitimlerine ve klinik yeteneklerine güvendiklerini göstermektedir. 5. sınıf öğrencilerinin \%97'si ve 4. sınıf öğrencilerinin yüzde \%94'ü, oral iltihabı gidermenin başarısız olmasının sistemik iltihaplanmaya katkıda bulunabileceğini anlamıştır. Ayrıca, 5. sınıf öğrencilerinin $\% 97$ 'si ve 4 . sınıf öğrencilerinin $\% 92$ 'si diyabet ve periodontal hastalık arasındaki çift yönlü ilişkiyi doğru olarak kabul etmiştir. Çalışmamızın bulguları literatürde bulunan benzer çalışmalar ile aynı doğrultudadır. ${ }^{10,14}$

Çalışmamızda elde edilen veriler ışığında risk faktörleri bilgisi, sistemik koșulların doğru tanımlanması büyük oranda son sınıflarda artış göstermiştir. 4. ve 5. sınıf öğrencilerinin her iki dönemde de \%40 ve üzerinde seçtiği üç risk faktörü: Kontrol altında olmayan diyabet, $\geq 6 \mathrm{~mm}$ posterior cep ve sigara kullanımı 'dır. Ayrıca, 5. sınıf öğrencilerinin dönem sonunda sınıf II furkasyon defektini risk faktörü olarak seçme oranı istatistiksel olarak anlamlı dercede artmıştır $(p<0.05)$. Ilginç olarak kontrol altında olmayan diyabet cevabı 4. Sınıflar \%60 oranında dönem başı ve sonunda tercih edilirken, 5 . sınıflarda bu oran dönem başında \%59 iken dönem sonunda \% 52 olarak işaretlenmiştir. 'Daha önce yapılan diş yüzeyi temizliği, kök yüzey düzleştirmesine cevap vermeyen hasta' sorusuna 4. sınıflar $\% 35^{\prime}$ den $\% 70$ 'e yükselen bir doğru cevap sayısı olsa da, 5. sınıflarda bu oran dönem sonunda \%61'den $\% 45^{\prime}$ e düşmüştür.

Öğrencilerin büyük çoğunluğu kardiyovasküler hastalık, ailesel periodontal hastalık öyküsü, çoklu ilaç kullanımı, mobilite ve yüksek plak skorunu çok yüksek oranda (\%100) en önemli risk faktörü olarak tanımlamışlardır. Bunların bir kaçı destekleyici periodontal tedavi için yapılan analizler içerisinde yer alan parametreler olsada öğrencilerin tek başlarına kontrol altına alabilecekleri durumlardır.

Klinik senaryolar ile ilgili sonuçlara bakıldığında, öğrencilerin büyük oranda mukogingival defektleri tanımada yetersiz olduğunu ortaya koymaktadır. Verilen senaryoda ön bölgede mukogingival problemi ve posterior bölgede $\geq 6 \mathrm{~mm}$ cebi olan hastaya çalışmaya katılan 4.sınıf öğrencilerinin \%20'si ve 5 sınıf ların \%9,5'u bir uzmana yönlendirme cevabı vermişlerdir. 4. sınıf öğrencilerinin $\% 47,5^{\prime}$ u dönem başında ve 5 . sınıf öğrencilerinin $\% 59,5^{\prime} i$ dönem sonunda $\geq 6 \mathrm{~mm}$ posterior cebi risk faktörü olarak tanımlarken bu teorik bilgiyi kliniğe aktarmada başarısız olmuşlardır.

Benzer şekilde HgA1c oranı 7 ve molar interproksimal bölgelerinde $6 \mathrm{~mm}$ derinliğinde cepleri olan bir hastaya
\%82 oranında 5. sınıf öğrencisi kendileri tarafından tedavi edilebileceği cevabını vermiştir. Risk faktörleri içerisinde öğrenciler tarafından kolaylıkla tanımlanan diyabet, klinik senaryoda gözden kaçması öğrencilerin limitasyonlarını bilme konusunda teorik bilgiyi kliniğe yansıtamadıklarını göstermektedir. Bu çalışmanın sonuçları, öğrencilerin periodontal tedavide limitasyonlarını bilme konusunda için temel bilgileri klinik senaryolara uygulayamadıklarını göstermektedir.

Her ne kadar bu çalışmada kullanılan anket, öğrencilerin bilgilerini, tutumlarını ve yönlendirme yeterliliklerini değerlendirmek için geliştirilmiş olsa da, anlamlıı̆ıı ve kullanılabilirliğin doğrulanması için daha büyük bir örnekleme intiyaç vardır. Bu bağlamda anketin ulusal çapta öğrenci ve mezunları da kapsayarak genişletilmesi daha anlamlı sonuçları da beraberinde getirebilecektir.

Bu çalışma, öğrencilerin periodontal hastalıkları etkileyen kritik hastalıkları ve risk faktörlerini

oldukça iyi bildiklerini ve tedavi konusunda özgüven sahibi olduklarını ortaya koymuştur. Buna karşın bilgi ile uygulamalı klinik muhakeme kurma arasında bir boşluk olduğunu göstermiştir. Öğrenciler risk faktörlerini analiz etmedeki becerilerini klinik senaryolarda kullanamamışlardır. Bu bulgular, dişhekimliği müfredatlarının periodontal hastaların yönetiminde öğrencilerin limitasyonlarını bilme ve teorik bilgiyi kliniğe yansıtmada daha vurgulayıcı olması gerektiğini göstermektedir.

\section{KAYNAKLAR}

1. Savage A, Eaton KA, Moles DR, Needleman I. A systematic review of definitions of periodontitis and methods that have been used to identify this disease. J Clin Periodontol 2009; 36: 458-467.

2. Kassebaum NJ, Bernabe E, Dahiya M, Bhandari B, Murray $C J$, Marcenes W. Global burden of severe periodontitis in 1990-2010: a systematic review and meta-regression. J Dent Res 2014; 93: 1045-1053.

3. Humphrey LL, Fu R, Buckley DI, Freeman M, Helfand $M$. Periodontal disease and coronary heart disease incidence: a systematic review and meta-analysis. Journal of general internal medicine 2008; 23: 2079.

4. Genco RJ, Borgnakke WS. Risk factors for periodontal disease. Periodontol 2000 2013; 62: 59-94.

5. Krebs KA, Clem DS, 3rd. Guidelines for the management of patients with periodontal diseases. J Periodontol 2006; 77: 1607-1611.

6. Borgnakke WS. Does treatment of periodontal disease influence systemic disease? Dental Clinics 2015; 59: 885917.

7. Lee JH, Bennett DE, Richards PS, Inglehart MR. Periodontal referral patterns of general dentists: lessons for dental education. Journal of Dental Education 2009; 73 : 199-210.

8. Tonetti MS, Jepsen S, Jin L, Otomo-Corgel J. Impact 
of the global burden of periodontal diseases on health, nutrition and wellbeing of mankind: A call for global action. Journal of clinical periodontology 2017; 44: 456-462. 9. Dockter KM, Williams KB, Bray KS, Cobb CM. Relationship between prereferral periodontal care and periodontal status at time of referral. J Periodontol 2006; 77: $1708-1716$.

10. Williams KB, Burgardt GJ, Rapley JW, Bray KK, Cobb $\mathrm{CM}$. Referring periodontal patients: clinical decision making by dental and dental hygiene students. J Dent Educ 2014; 78: 445-453.

11. Sanz M, Meyle J. Scope, competences, learning outcomes and methods of periodontal education within the undergraduate dental curriculum: a consensus report of the 1st European workshop on periodontal educationposition paper 2 and consensus view 2. Euro J Dent Educ 2010; 14: 25-33.

12. Krebs KA, Clem DS. Guidelines for the management of patients with periodontal diseases. J Periodontol 2006; 77: 1607-1611.

13. John V, Lee S-J, Prakasam S, Eckert GJ, Maupome G. Consensus training: an effective tool to minimize variations in periodontal diagnosis and treatment planning among dental faculty and students. J Dent Educ 2013; 77: 1022-1032.

14. Friesen LR, Walker MP, Kisling RE, Liu Y, Williams KB. Knowledge of risk factors and the periodontal disease-systemic link in dental students' clinical decisions. J Dent Educ 2014; 78: 1244-1251. 